\title{
Research on the Development of "Internet + Experiential Tourism" of Tangshan Hot Spring Tourist Resorts
}

\author{
Xiumei Miao, a , Peng Peng ${ }^{2, \mathrm{~b}}$ and Chuanmin $\mathrm{Mi}^{2, \mathrm{c}, ~ *}$ \\ ${ }^{1}$ Business School, Hohai University, Nanjing, China \\ ${ }^{2}$ College of Economics and Management, Nanjing University of Aeronautics and Astronautics, \\ Nanjing, China \\ a njjycgs@163.com, ${ }^{\mathrm{b}} 1621223590 @ q q . c o m,{ }^{\mathrm{C}}$ Corresponding Author: cmm@ieee.org
}

\begin{abstract}
Keywords: Hot Spring Tourist Resort; Internet +; Experiential Tourism; Development Mode. Abstract. As an important part of the tertiary industry, the tourism industry needs to realize the integration of internal elements and the connection of external resources through "Internet + " to adapt to the development of the new economic era. Taking Tangshan Hot Spring as an example, discussed practical significance of development of the hot spring resorts, and proposed a new "Internet + Experiential Tourism" development mode, gave some suggestions for its development.
\end{abstract}

\section{Introduction}

The Third Plenary Session of the 12th National People's Congress opened on March 5, 2015 at the Great Hall of the People, in which Premier Li Keqiang proposed the development of the "Internet +" action plan. In August 2015, the General Office of the State Council issued the Several Opinions on Further Promoting Tourism Investment and Consumption that called for the positive development of "Internet + Tourism." On the other hand, as the experience economy era comes, an increasing number of tourist destination operators begin to pay attention to the meaning of tourism behavior for tourists, considering the demands of tourists to different tourism experience in many regards [1]. As another emerging tourism industry following natural scenery, theme parks, sightseeing and large casino, the hot spring tourism develops rapidly, known as the "Sunrise in the Sunrise Industry". Hot spring is the best carrier for the development of healthy tourism and enjoys a huge space for development in spa, rehabilitation, chronic diseases and occupational diseases prevention, treatment and health maintenance. As one of the best choices for recreational tourism, the hot spring tourism is much favored by the majority of tourists [2]. Tangshan Hot Spring takes the lead in four major spa areas of China. As the world renowned spa area, it is the only one in China with European and Japanese hot spring water quality certification, with the reputation of "Health Maintenance Paradise with Millennium Holy Soup". Tangshan Hot Spring Tourist Resorts was rated as "The Best Recreational Tourism Destination in China" in 2014 and emerged as one of the first batch of national tourism resorts in October 2015, with unique advantages and great potential in the promotion and expansion of hot spring tourism and health spa industry.

Against the background of the rapid development of "Internet +", the development idea on "Internet + Experiential Tourism" is presented in this paper, expounding the practical significance of the development of "Internet + Experiential Tourism" in the hot spring resorts. Then, taking Tangshan Hot Spring as an example, this paper will study on the development mode on the perspective of development management and brand building of the hot spring resort, focus on the promotion of tourists behavior and user experience, with suggestions for its development put forward finally.

\section{Literature Review}

China is extraordinarily abundant in hot spring tourism resources, which means that they are rich in variety and quantity. 2,700 available hot spring locations can be exploited, leading China to be one of the countries with the most hot springs worldwide. With China's hot spring tourism stepping into the development stage of mass tourism, hot spring tourism development is not limited to the spa medical 
function, but begins to expand to the multi functional and comprehensive hot spring tourism development [3]. Yu Yan believes that the traditional business model shall be shifted in the current development of the hot spring tourism, which shall not only focus on indoor development, but also be moved to the outdoors, so that tourists can experience the beauty in the nature and the hot spring at first hand [4]. Wang Hua and Peng Hua comprehensively analyze the main factors affecting the development of the hot spring through a large number of empirical investigations and literature review [5].

In the book of Future Shock, Toffler points out that "Experience Economy" is a service economy at a higher level, mainly obtaining profits through the creation of personalized life and business experience. It is an economic form following agricultural economy, manufacturing economy and service economy [6]. Prentice and Witt have summed up five theories in the study of tourism experience from the integration of viewpoints: (1) the hierarchical theory of experience; (2) the standard theory of experience; (3) the goal directed behavioral theory; (4) the multi type theory; (5) the insider-outsider theory [7]. Experiential tourism development means that tourism planners are required to select the appropriate target market of the tourist destination and make clear in one or several combined experience fields preferred by customers on the basis of full market survey and finding and understanding the experience needs of tourists, with corresponding landscape design and feeling atmosphere created according to the expected experience effect [8].

Pony Ma points out that "Internet + " represents the future, which is a new way of life and production and even a trend of social formation changes [9]. As an important pillar industry of national economic development, the tourism industry needs to realize the integration of internal elements and the connection of external resources through the "Internet + " to adapt to the development of the new economic era. On September 16, 2015, the National Tourism Administration puts forward the requirements for the implementation of "Tourism + Internet" action plan: by 2020, to achieve full integration can be realized in all fields of tourism industry with the Internet that serves as the main driving force and important support for innovation and development of domestic tourism; online tourism investment accounts for $15 \%$ of the national direct tourism investment, and online tourism consumption expenditure accounts for $20 \%$ of the national tourism consumption expenditure. Hot spring resort development shall make efforts in integration with "Internet + ", identifying the important form and carrier combined with hot spring tourism and building the tourism network infrastructure, the tourism E-commerce platform and the tourism Internet business ecosystem of the hot spring resort in ways that put hot spring tourism products on the market at the fastest speed and improve economic returns.

\section{The Development Mode of "Internet + Experiential Tourism"}

\section{(1) Big Data Mode of "Internet + Experiential Tourism"}

Big data can not only predict and manage the tourism market supply and demand, response rapidly to the demands of users and apply small density data to create personalized service, but also carry out difference analysis of tourism products and service levels in various places to make scientific evaluation and decision.

\section{(A) Big Data Mode of "Internet + Experiential Tourism"}

The tourism management platform of the hot spring resort is established, with the use of the Internet, Internet of Things, cloud computing, radio frequency technology for timely releasing tourism resource actions of the hot spring resort and other information to realize automatic and intelligent tourism management, marketing and service in ways that provide tourists with more comfortable tourism experience.

On the construction of business service platform, the big data monitor tourist actions in the hot spring resort, which can provide not only scenic flow data to guide tourists to travel separately, but 
also guest source structure data for the scenic area. Data analysis can provide scientific basis for the management decision of the scenic area and the marketing decision.

The tourism management application system of the hot spring resort develops towards the intelligent direction, including the establishment of information service system, supervision and management system, emergency command system and prevention system.

\section{(B) Big Data Mode of Tourist Behavior Analysis}

Through the integrated analysis of the big database of tourist information, personalized services are provided so that the potential demands of consumers can be transformed into the actual consumption in a large scale and high efficiency manner, which is the center of "large scale personalized interaction", as well as the value of the big data analysis. The big data analysis mode of the hot spring experiential tourism grasps a large number of accurate tourist information for data consolidation in ways that extract the characteristics of tourists or opinions to complete the development of new tourism products, or that realize further powerful combination with the social platform to open the further promotion channel after inviting participants to experience. In another perspective, this mode also uses the social platform to transfer the tour value directly to the users. The precise analysis and image description of the user value allow the user needs to match with the tour value more directly, more accurately and faster. During this process, consumption, data, marketing and effects compose a closed loop marketing mode with data flow as a standard. This marketing mode not only enjoys clear objectives, but also allows marketing activities to be optimized, measured and tracked under the role of data, so that all marketing and consumer behaviors emerge as data.

"Internet + Experiential Tourism" allows more tourism resources and tourism information to be shared. It serves as an important platform for the marketing experience of tourism products. "Internet + Experiential Tourism" of the hot spring resort prompts tourism consumers to experience sharing and tourism comments in time. The groups that do not know each other can share the tourism consumption experience of the hot spring tourism project that both are interested in through the platform, and then the follow up market experience effects of the tourism consumption experience are formed, resulting in a certain cycling experience effects in ways that affect the tourism consumption in the hot spring resort.

\section{(2) The Internet Mode of the Brand Building}

\section{(A) Five-in-one Promotion Mode}

The Internet is used to build its own unified, comprehensive website for the hot spring experiential tourism. The experiential tourism resources of Tangshan Hot Spring are gathered in this platform (shown in Fig. 1) to share the tourism data. The PC-terminal website is mainly about tourism promotion of the hot spring resort for its characteristics and highlights, supplemented by travel reservation, online transactions and other functions. An App platform of the mobile terminal is built, centered on $\mathrm{O} 2 \mathrm{O}$ service function, including ticket reservation, hotel reservation, catering and entertainment reservation and self-driving service reservation. Joint promotion shall be made with third party electronic commerce platform, such as planning of theme activities like "hot spring tourism festival" and selling of related quality tourist routes. The network new media and new applications shall be used completely. The official APP, the official micro-blog, the official WeChat, the official Tmall shop and other application software shall have an in-depth integration with tourism consultation promotion and product marketing of the local hot spring resort. Meanwhile, it shall cooperate with travel agencies to carry out team tour for hot spring experience, building the complete and systematic network platform promotion system of "Internet + Experiential Tourism" for the hot spring resort. 


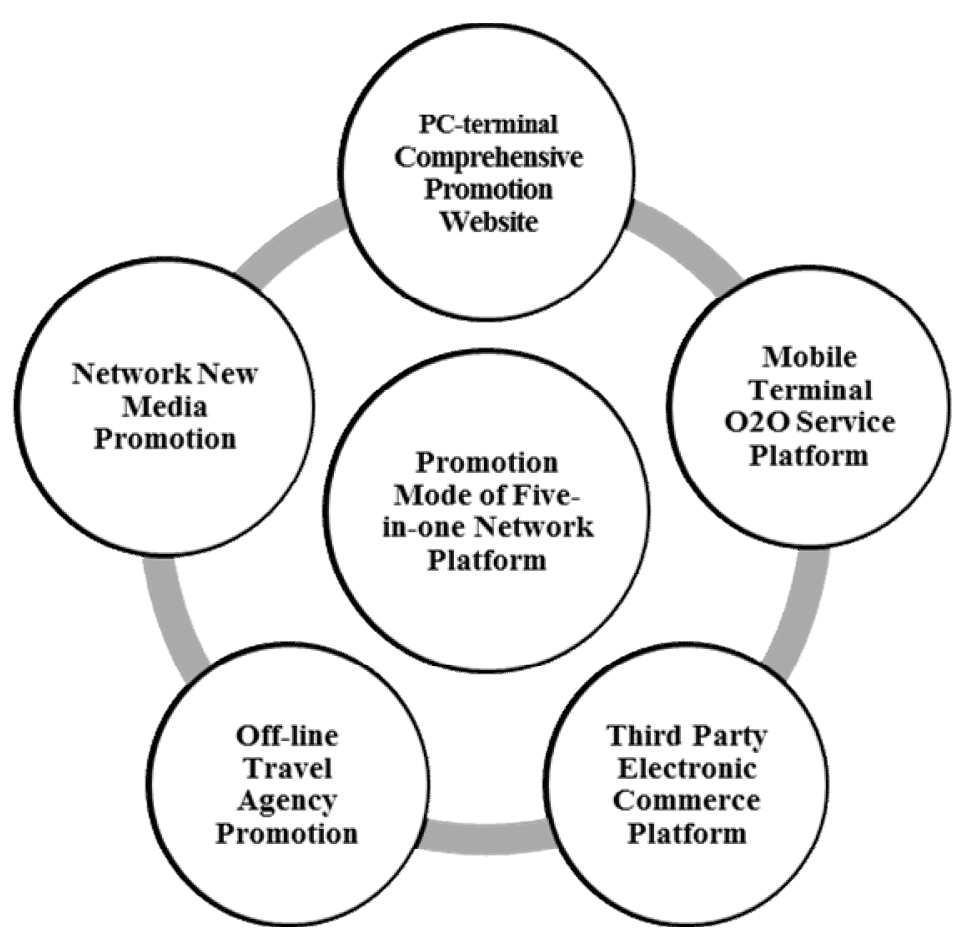

Fig. 1 Structure of "Five-in-one" Promotion Mode

\section{(B) VR Experiential marketing mode}

VR is a technology that comprehensively use the computer graphics system and a variety of real and control interface devices to provide an immersive feeling in the interactive three dimensional environment generated on the computer. Traditional tourism promotion of the hot spring resort includes "TV and network platform advertising + exhibition + introduction and marketing event" that are the visual guidance on the plane. VR technology can be used to improve the experience of tourists, so that tourists can contact with the tourist destination visually and acoustically in an all-round manner to experience the destination before the purchase of tourism products virtually. "VR + hot spring tour" experiential marketing mode will use the original sales statement, image video information to introduce the recommended way for traditional hot spring tourism products in ways that provide a more intuitive way for the hot spring tourism enthusiasts in the route selection before the tourism. On the one hand, it can cooperate with the local travel agencies to build the VR exhibition hall for the hot spring experiential tourism in major travel agencies of various regions, and tourists can enjoy the pre-tourism experience through VR technology before buying the experiential tourism products of the hot spring; on the other hand, VR display function shall be added to the APP described above.

\section{Suggestion of "Internet + Experiential Tourism" of Tangshan Hot Spring Tourist Resorts}

The rapid development of "Internet + " will provide an important development opportunity for the transformation and upgrading of Tangshan Hot Spring tourism industry and spanning improvement of spa health industry. With regard to the development mode of "Internet + Experiential Tourism" provided in the fourth part, the following development proposals can be put forward for "Internet + Experiential Tourism" of Tangshan Hot Spring Tourist Resorts.

\section{(1) Strengthen the Internet Infrastructure Construction}

The Internet infrastructure construction of hot spring experiential tourism area shall be promoted to ensure that infrastructure conditions of "Internet + Experiential Tourism" in the hot spring resort are met. Promote the building of the relevant information terminal of the hot spring experiential tourism and other equipment systems are promoted. In the airport, the station, the terminal, the hotel, the scenic spot, the tourism shopping center, the tourist center and other main tourism places, the touch screen and other tourist information interaction terminals are provided so that it will be more 
convenient to access and use Internet information services and online interaction for tourists. With reference to smart tourist attraction standards, full coverage of free WIFI, intelligent tourism guide, electronic explanation, online booking, information push and other functions can be realized.

(2) Deepen the Cooperation of Tangshan Hot Spring Tourist Resorts with Internet Enterprises The investment and financing innovation of "Internet + Experiential Tourism" shall be promoted to guide social capital involving in the "Internet + Experiential Tourism" field, to encourage the integrative development of tourism enterprises and Internet companies through strategic investment and other market oriented means and to build the development mode with online and offline combination and investment combined with brands. Online tourism startup and innovation are supported, with various innovative actors encouraged to make full use of the Internet in ways that carry out tourism demand oriented plan; tourism innovation platform, maker space, innovation base and other new mass innovation space development for tourism are supported to enhance the innovation ability of "Internet + Experiential Tourism".

\section{(3) Enhance the Internet Application Capability}

The Internet and mobile Internet are used to enhance the management, service and marketing level of the hot spring experiential tourism. The electronic commerce platform of the hot spring experiential tourism is developed actively to encourage regions to use the Internet to carry out the marketing information release of the hot spring experiential tourism and online booking and transaction of hot spring experiential tourism products. The hot spring experiential tourism destination is supported to use the big data for tourism in exploring analysis means as a way to establish the marketing system for the hot spring experiential tourism destination that radio, television, newspapers, multimedia and other traditional channels are combined with mobile Internet, micro-blog, WeChat and other new media channels. Hot spring experiential tourism enterprises are encouraged to cultivate regular customer, enhance the enterprises' precise marketing capabilities and stimulate market consumption demands through micro-blog, WeChat and other new media network means.

\section{(4) Innovate the Experiential Tourism Project}

With Tangshan Hot Spring as the carrier and enriching the promotion of the tourist experience as the core, relevant industries can be grafted effectively, such as "hot spring + Chinese medicine health keeping", "hot spring + happy with leisure", "hot spring + human experience" and so on. Emphasis shall be made on creating high quality resort environment to provide diversified, high grade wellness tourism products. On the one hand, the scenic management of the core area in the resort area can be realized to explore the establishment of market oriented management system, on the other hand, the opportunity for the new urbanization pilot shall be seized, with the transformation of small towns and old streets as the focus, to speed up the construction of the tourist town for hot spring health culture and actively integrate into the Internet thinking and "e hot spring" vision to create the hot spring town with Internet characteristics for developing the new mode of "Internet + Experiential Tourism".

\section{Acknowledgements}

This work was financially supported by the Project of National Social Science Foundation of China (17BGL091), the Fundamental Research Funds for the Central Universities of China (NS2016078).

\section{References}

[1] Messerli H. R., Oyama Y.: Health and wellness tourism-global. Travel and Tourism Analyst, Vol. 8 (2004), p. 1-54.

[2] Diedrich A., García Buades E.: Local perceptions of tourism as indicators of destination decline. Tourism Management, Vol. 30, (2009), p. 512-521. 
[3] Chon K. S., Mathies C., Weiermair K., Mathies C.: The tourism and leisure industry: shaping the future. Annal of Tourism Research, Vol 32, (2005), p. 510-511.

[4] Yu Y.: The development analysis of China tourism. Market Weekly, Vol. 12 (2008), p. 41-42.

[5] Wang H., Peng H.: A comprehensive analysis of the main influential factors in development of Spa tourism. Tourism Tribune, Vol. 19 (2004), p. 51-55.

[6] Toffler A.: Future shock. American Journal of Sociology, Vol. 77 (1971), p. 104.

[7] Prentice R. C., Witt S. F., Hamer C.: Tourism as experience: The case of heritage parks. Annals of Tourism Research, Vol. 25 (1998), p. 1-24.

[8] Wang S., Harrill R.: An Empirical Study on the Residents' Perception and Attitudes toward Tourism Impact: a Case study from Shandong Province, China. Tourism Science, 2009,

[9] Ma P.: Internet Plus- National Strategic Roadmap for Action (CITIC Press, China 2015). 